\section{Medicare's new prescription drug plan causes confusion}

\author{
Fred Charatan Florida
}

More than 43 million US senior citizens have started choosing a new prescription drug plan under the biggest change to the country's Medicare scheme since 1965. But many are finding the choice of different schemes bewildering.

Senior citizens can join without penalty as late as 15 May 2006 , but for coverage to begin by 1 January 2006, they must select by the end of this year. The drug benefit is going to cost an estimated \$724bn (£421bn; €615bn) over 10 years, as senior citizens have on average six prescriptions each. Some say it is President Bush's biggest domestic achievement. Up to now, the Medicare scheme, which provides health insurance for senior citizens, has reimbursed only a limited number of drugs.

The federal Centers for Medicare and Medicaid Services have issued an official 100 page handbook entitled Medicare E $\mathcal{F}^{\circ}$ ou
2006 to every Medicare beneficiary. It explains that insurance companies and other private companies are working with Medicare to offer the plans.

Comparing one plan with another is confusing, because people enrolling must balance how much risk they are willing to absorb, against how much they are willing to pay in monthly premiums ranging from $\$ 10$ to $\$ 70$. Each insurance company offers different plans, varying from state to state.

On 13 November 2005, the front page headline in the New York Times said, "Confusion is rife about drug plan as sign-up nears." When asked about beneficiaries confusion, Michael Leavitt, secretary of the US Department of Health and Human Services, said, "Health care is complicated. We acknowledge that.

"Lots of things in life are com-

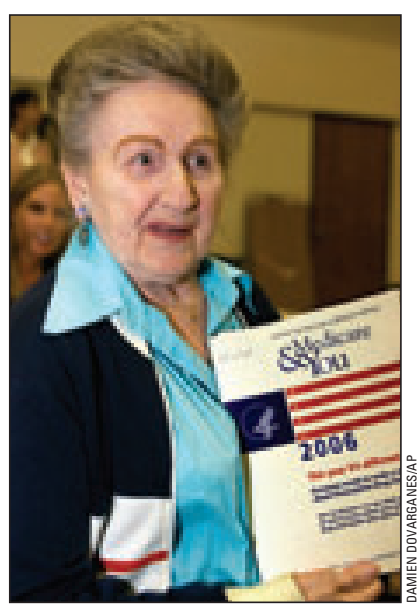

Josephine Slosky complains about the complexity of Medicare plans at a meeting in California

plicated: filling out a tax return, registering your car, getting cable television. It is going to take time for seniors to become comfortable with the drug benefit."

In fact, more than $61 \%$ of seniors say that they don't really understand the benefit, according to a survey released last week by Kaiser Family Foundation, a non-profit foundation focusing on health care, and the Harvard School of Public Health. Only $20 \%$ of those polled said that they plan to enrol.

The yearly deductible charge (the amount the enrollee must pay before the plan starts to pay for any medicines) varies up to $\$ 250$. If the total drug costs in 2006 add up to $\$ 2250$, Medicare covers most of the drug costs. After that, enrollees must pay all costs out of their own money for brand name drugs until they reach $\$ 5100$, a threshold that has been nicknamed "the doughnut hole." After that, the "catastrophic drug coverage" scheme automatically pays $95 \%$ of remaining costs until the end of the year.

If only $20 \%$ or even $30 \%$ of senior citizens sign up, that will bode ill for the future of the programme, because the people most likely to sign up are the people with high drug expenses. "You don't have insurance if you don't spread the risk among people who are healthy," said John Rother, policy director of the American Association of Retired Persons.

\section{Drug industry's new code criticised for lacking teeth}

\section{Rebecca Coombes London}

The pharmaceutical industry published a tougher code of conduct this week after criticism that self regulation was failing to stop the circulation of misleading claims about products. The revised code from the Association of the British Pharmaceutical Industry follows a critical health select committee report in April (BMJ 2005;330:805).

As evidence that self regulation wasn't working well, the report cited examples of breaches of advertising regulations; cover-ups of negative medical information; and giving misleading information to prescribers. MPs also criticised the long delays taken by the industry to investigate complaints.

As with previous codes, the new code of conduct, to be launched in January, is a voluntary code, without the backing of the law. It covers communication with the public and the promotion of prescription only medicines to health professionals. The main changes include a tightening of rules governing hospitality so that delegates sponsored by companies to attend meetings must only be given economy airline tickets and should not be put up in "lavish" accommodation. The new code stops short of banning four or five star hotels, however.

The code says that all printed promotional material should now include prominent information about reporting adverse drug reactions. The permitted number of pages of medical advertising for a drug has been reduced from three to two pages. There is also an outright ban on promotional competitions because they "trivialise the information about medicines."

On marketing, companies must make no more than three mailings in the first six months of a drug launch. Each drug has an overall limit of eight mailings a year.

The code promises to speed up complaints procedures and powers to suspend materials even if a company is appealing against a board decision. In serious cases, the association would take out advertisements in the medical press condemning those companies that had broken the code. The code does not, however, introduce fines for companies.

Andrew Hotchkiss, an association board member and managing director of Lilly UK, said, "The key thing for us is the reputation of the industry. 'Naming and shaming' is the biggest sanction. At the end of the day any company can pay a finewhether it be $£ 100$ [\$172; €146] or $£ 10000$ but more valuable is the company's reputation."

Breaches of the code are dealt with by the industry's Prescription Medicines Code of Practice Authority. Last year the authority considered 120 complaints, mostly from health professionals, and 88 were ruled as in breach of the code, mainly complaints related to printed promotional material.

Some people have doubts over the supposed strength of the new code, however. Ike Iheanacho, editor of the Drugs and Therapeutics Bulletin, said, "This has been heralded as a new dawn in the promotion of prescription medicines and allied activities. But the problem is that the code is fundamentally weak because the ultimate sanction a company faces for breaking it is very limited."

The ultimate sanction for a company breaking the code is expulsion from the Association of the British Pharmaceutical Industry, and this has never happened. The board has also never required a company to publish a corrective statement. "They can make token changes but the key weakness is that this is regulated by the industry, and so it is written in such a way that it doesn't seriously inconvenience companies if anything goes wrong," he said.

Professor Andrew Herxheimer, emeritus fellow at the UK Cochrane Centre, said, "It's a very determined sales job on the new code-just like a drugs promotion. But what does it mean in substance? You need to look at what is missing. This is very competent window dressing but not much has changed at all."

The health select committee's report, The Influence of the Pharmaceutical Industry, is available at www.publications.parliament.uk. 